\title{
Imaginações sul-americanas
}

\section{Iara Sydenstricker ${ }^{1}$}

RESUMO: Tendo em vista as obras Poética do espaço (1989) e $O$ direito de sonhar (1986), de Gaston Bachelard, este ensaio propõe um exercício de imaginação material sobre a América do Sul, com o intuito de desenvolver perspectivas de criação dramatúrgica tendo por base o continente. Para isso, criou-se uma metodologia particular: (re)esculpindo-se a América do Sul, dela são retirados, um de cada vez, todos os seus países (incluindo o território ultramarino francês da Guiana). Uma a uma, são analisadas as imagens resultantes dessas amputações e alguns significados do vazio deixado por cada país. Finalmente, os mapas resultantes são girados em torno de seus eixos e imageticamente ressignificados.

Palavras-chave: América do Sul; criação; dramaturgia.

\begin{abstract}
Taking into account the works Poetics of space (1989) and The right to dream (1986), by Gaston Bachelard, it proposes an exercise in imagination over South America, for creating drama, with a particular methodology: (re) carving to South America, it is removed, one at a time, each one of its countries (including overseas territory of French Guyana). One by one, the resulting images are analyzed and some of these amputations meanings of the void left by each country. Finally, the resulting maps are rotated around their axes and imagetically reframe.
\end{abstract}

Keywords: South America; creation; dramaturgy.

\section{Introdução}

Este trabalho aposta numa criação não previamente organizada pela escrita, mas que se compõe a partir de imagens lavradas uma a uma através de ferramentas virtuais, cujos resultados discutem a imaginação como poesia e ampliação dos limites da vida: "Imaginar será sempre maior que viver” (BACHELARD, 1989, p. 100).

1 Doutora em Artes Cênicas pelo Programa de Pós-Graduação em Artes Cênicas da UFBA, roteirista, pesquisadora e professora na área do audiovi-
O objetivo deste exercício é contribuir para a criação de teledramaturgia ficcional que incorpore as diversas faces da América do Sul e que possa ampliar o universo narrativo da nossa televisão. Levando em conta questões como nomadismo, transnacionalidade, tradição, individualismo, redes de solidariedade, estruturas familiares, geografia fundiária, mitologias e cosmogonias do continente, e tendo em vista especificidades dos países que o constituem, busca-se uma primeira aproximação da casauniverso sul-americana. "Porque a casa é o nosso canto no mundo" (BACHELARD, 1989, p. 24). Casas onde moramos, casas derrubadas, erguidas, reerguidas, reformadas, desistidas, futucadas, como antigas casas do pai:

Lembro bem, sim lembro das velhas casas

Que marcaram minha infância distante. (Casas de aluguel... Em Minhas Gerais).

Mas de quase todas guardo inda bem

O cheiro de tintas frescas, mesclando

Odores da cal com leite azedado

Nas paredes com tinta d'óleo sobre

Portas e janelas. Cheiros [...]

Aromas e cheiros que me invocavam

Mistérios vizinhos por conhecer,

Porões e quintais contendo segredos

Espaços ocultos, várias fruteiras

Sucatas largadas pelos quintais,

Fontes para mil sonhos de menino

Travesso, querendo estudar o que foram

Ferros gastos, louças partidas [...]

De sonhos, travessos ou não, gostosas

Lembranças das casas antigas de

Minas com seus cheiros... Cal com leite e óleos.

(SYDENSTRICKER, Jack, 1996, p. 130)

Um exercício de imaginação material: esculturas com terra sul-americana

A metodologia deste exercício de materialização imagética é simples. Adotou-se como base única um mapa político-administrativo da América do Sul - matriz que gerou os demais mapas -, e dele foram subtraídos país por país, resultando, a cada subtração, numa nova forma para o continente. Imediatamente após a finalização de cada "amputação", foi anotada a primeira imagem que dela emanou. As primeiras impressões, 
apenas. Ao final, retomou-se a imagem da América do Sul inteira para, nela, proceder-se a uma viagem através de contornos, labirintos e rodeios, levando o andarilho a talhar percursos na terra continental.

Consideraram-se os 12 países (Argentina, Bolívia, Brasil, Chile, Colômbia, Equador, Guiana, Paraguai, Peru, Suriname, Venezuela e Uruguai) e também a Guiana Francesa, um território ultramarinho francês. Assim, obtiveram-se 13 mapas, que serviram de fonte imagética para o desenvolvimento de idéias sobre temas, perspectivas de futuro, riquezas, obstáculos, temores, alertas ecológicos, política e também personagens, tramas e desejos narrativos despertados por imagens da América do Sul.

Os países foram "recortados" em obediência ao sentido horário, iniciando pelo Uruguai até chegar ao Brasil, último país a ser "retirado" da América do Sul. Buscouse, de alguma forma (ainda que inconsciente), retificar a imagem do vazio deixado pelo desaparecimento do respectivo país. A principal preocupação estava não no vazio ou na forma dele resultante, mas no significado da ausência. O que significa o vazio de um país? $O$ que significa a retirada, a extirpação de um territóriocasa? Como lidamos com esse imenso lugar chamado América do Sul? Está sendo cuidado? Onde estão seus cantos, suas gavetas, seus cofres? Quais são os cheiros da América do Sul? As vozes, os tons e semitons de suas dermes, matas, águas... Como compreender sinais emanados por suas lendas, crenças, perigos, ameaças...? Quem é a América do Sul? Quem somos, América do Sul?

A dor da perda de cada país/território se faz notar pelo buraco escavado na América do Sul, nem todos da mesma proporção. Uns afrontosa e arrogantemente evidentes; outros, sub-repticiosamente fingem pequenez.

Apenas a ausência do Uruguai - talvez por ter sido o primeiro país extirpado neste fazer imagético - foi acrescida de uma imagem, a de uma gota d'água. Como se todo o continente, imerso em imensa tristeza, por ele tivesse derramado uma lágrima.

\section{América do Sul}

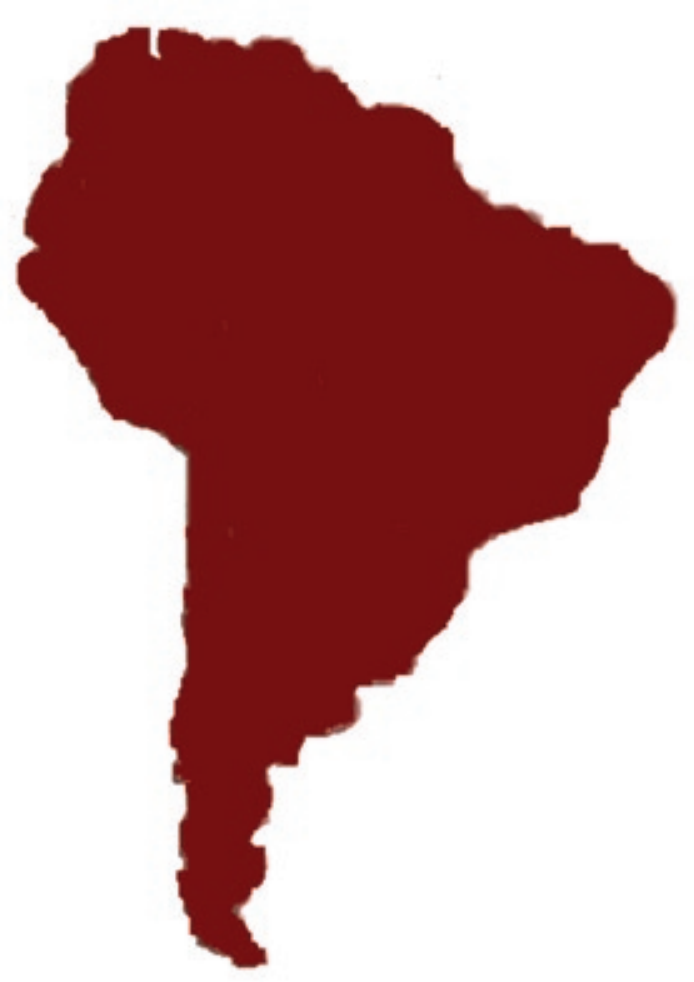

Como rebeldes, explodimos fronteiras de nacionalidade. Já não importam tanto as nacionalidades circunscritas, senão o que trazem de entrelaçamento, de tessitura rizomática entre as demais nacionalidades do continente. Importam os pertencimentos sul-americanos. Continente-casa, a América do Sul "abriga o devaneio, (...) permite sonhar em paz” (obra citada, 1989, p. 26). Em nosso sótão há sol, troncos, galhos, folhas, árvores, satélites a nos vigiar, aviões de todos os tipos, pássaros, macacos, antenas, sinais telefônicos, mensagens pirateadas, flechas e outras tantas coisas que rasgam o ar em sinfonias constituídas por imensas algazarras de sons, imagens, cheiros e tatos que mal conhecemos. São muitos os céus sul-americanos.

Em nosso porão escondem-se segredos, movimenta-se gente em subterrâneos escavados. Armazenam-se pedras, metais, arqueologias, raízes, petróleo, água. Temos o Aqüífero Guarani. Nossas catacumbas se comunicam (mas pouco sabemos sobre isso). Sim, há catacumbas na América do Sul. América-terra modelada em argilas muitas. Pátria que nos protege. Berço de mãe, manto de muitas Marias. 
A América do Sul sem o Uruguai. Chora. Sem a Argentina, se desfaz.
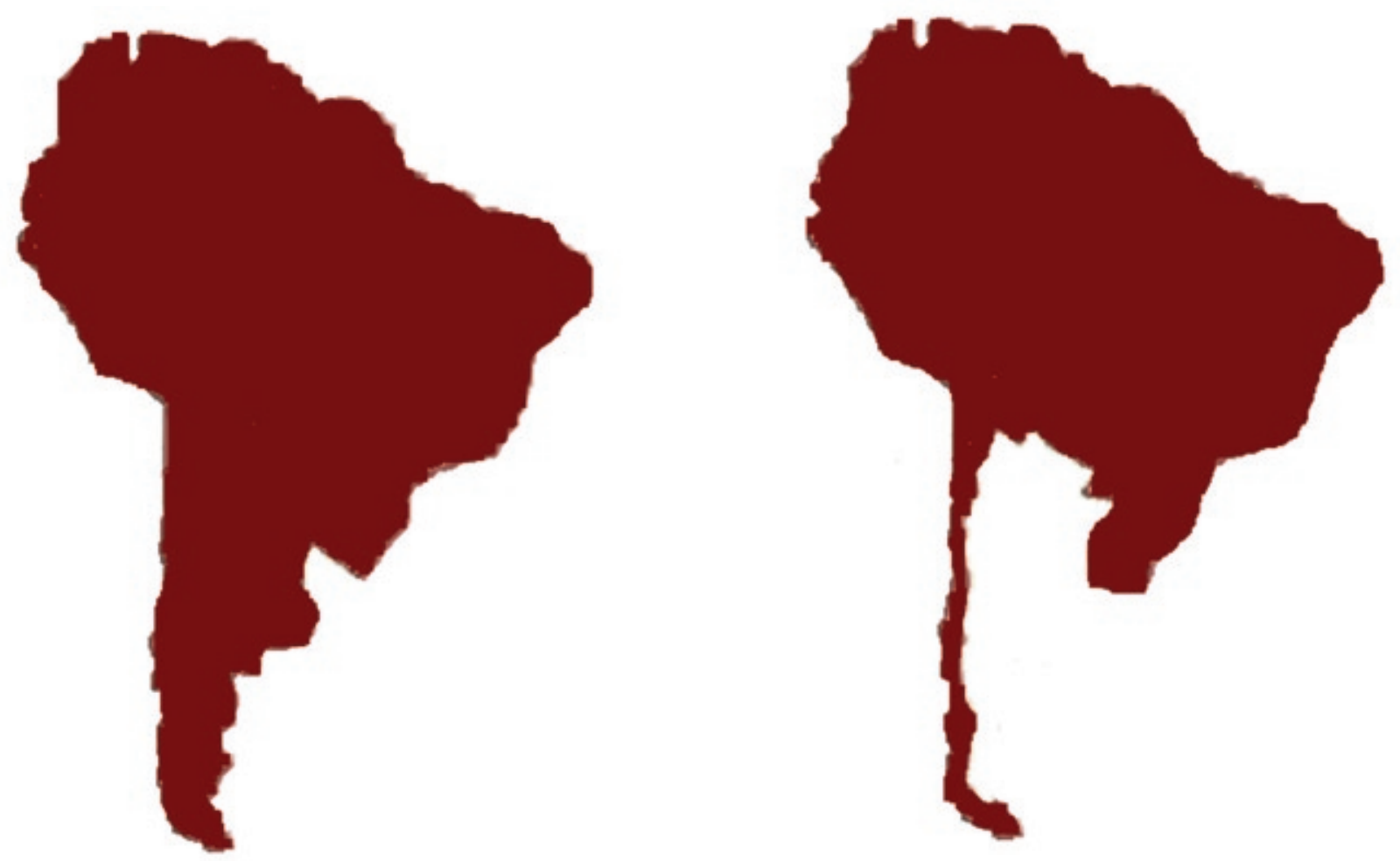

A América do Sul sem o Chile. Recua.

Sem o Paraguai, abre uma ferida no rosto.
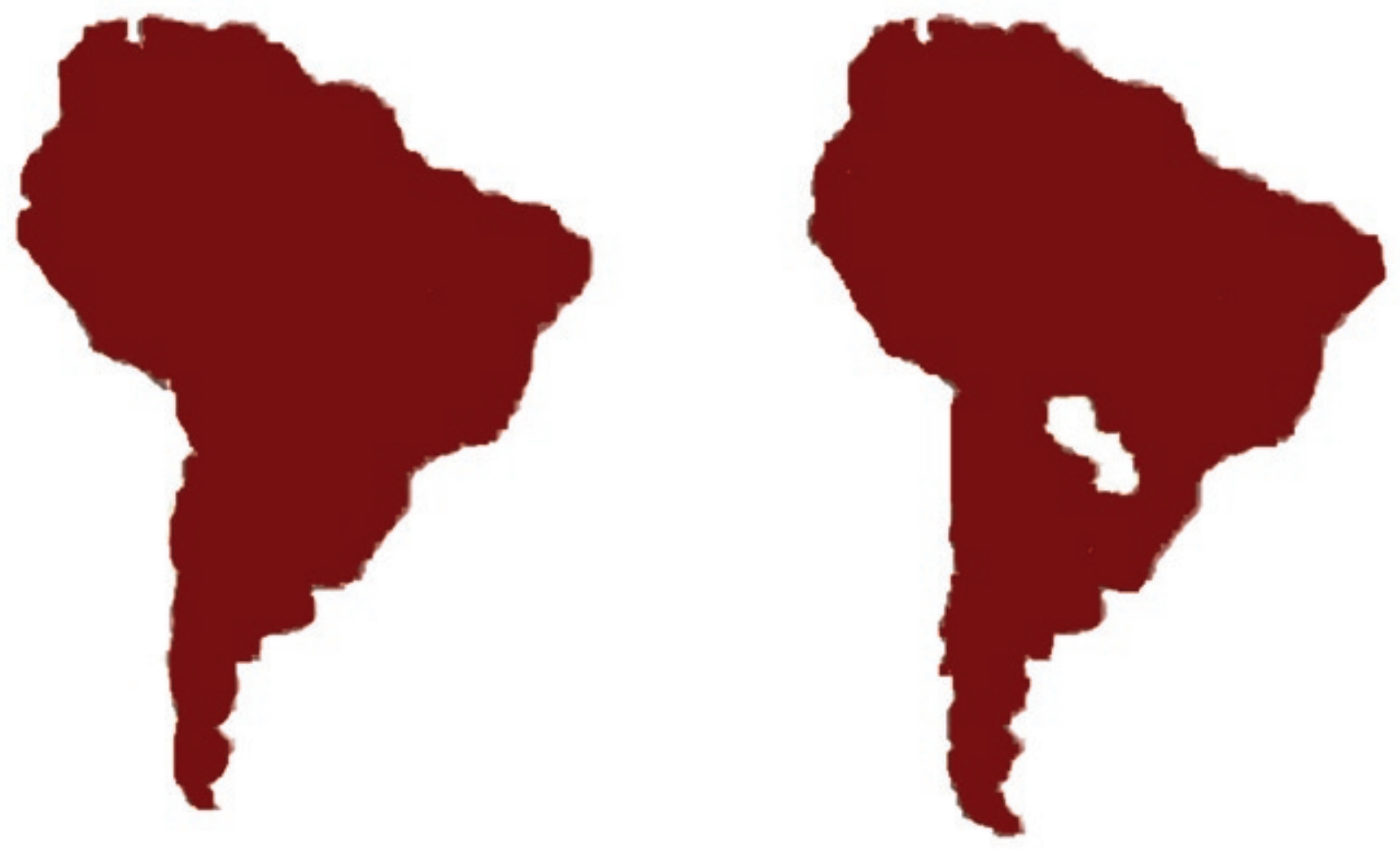
Sem a Bolívia. Emburrece, cria um oco de pensamento.

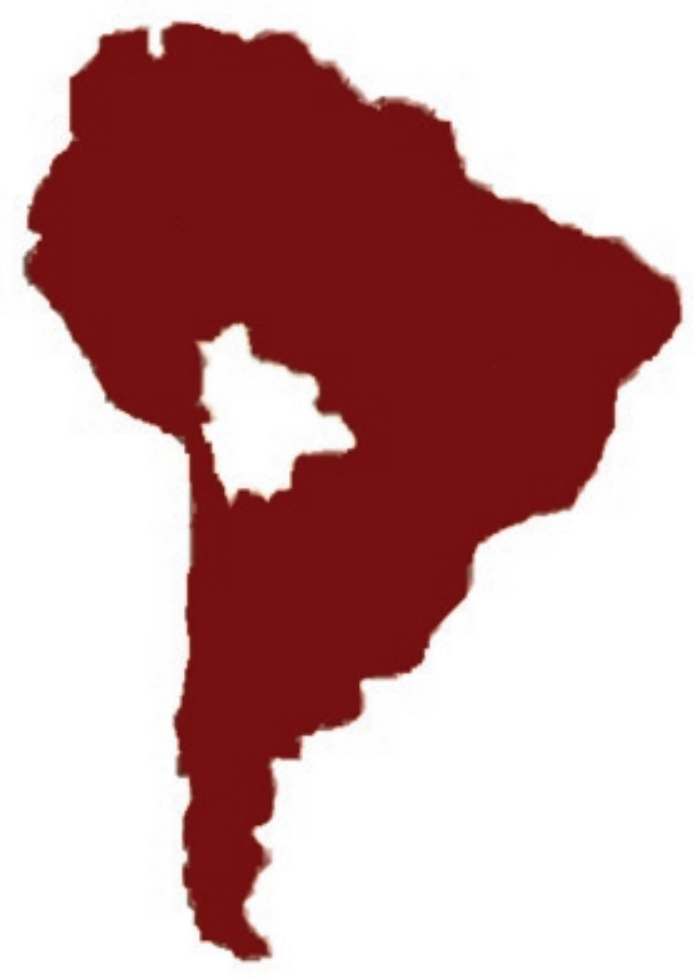

Sem o Equador, grita.

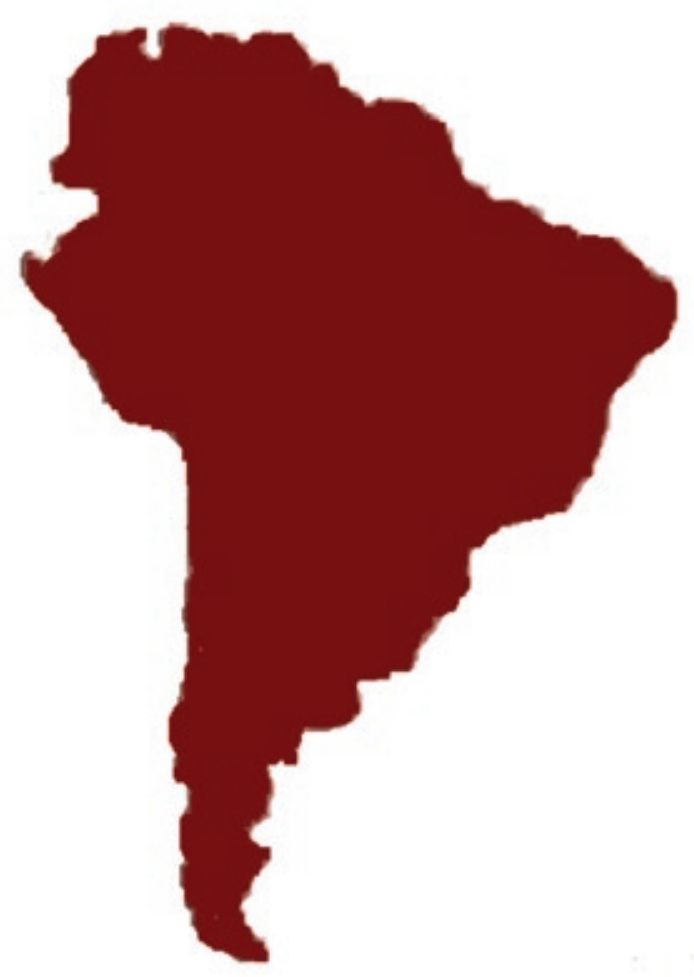

A América do Sul sem o Peru vira-se de costas para o Ocidente.

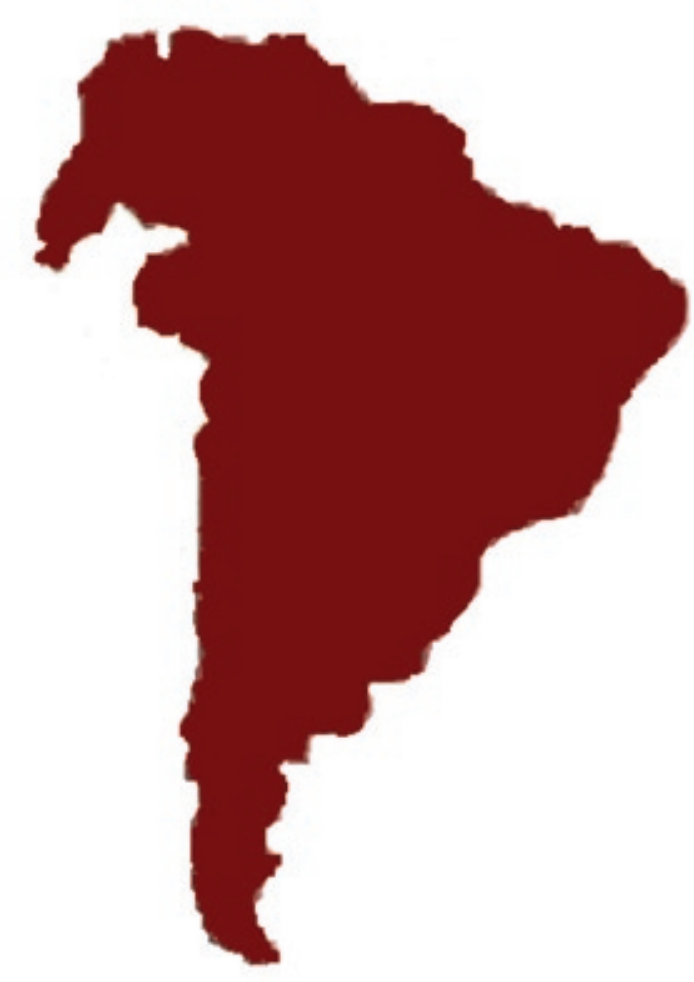

Sem a Colômbia, urra de dor.

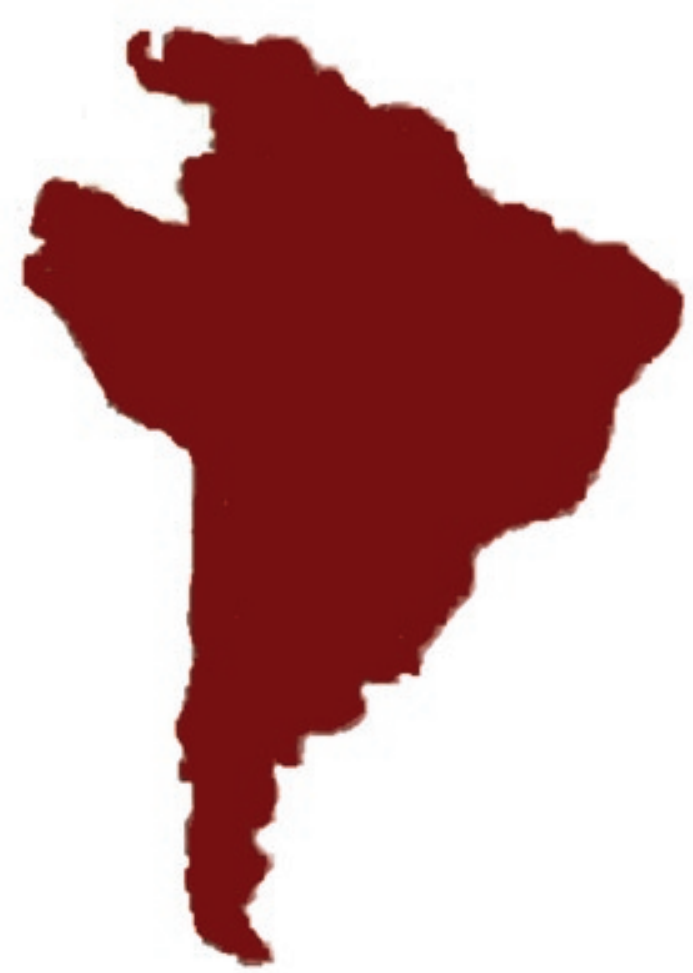


Sem a Venezuela, morde.

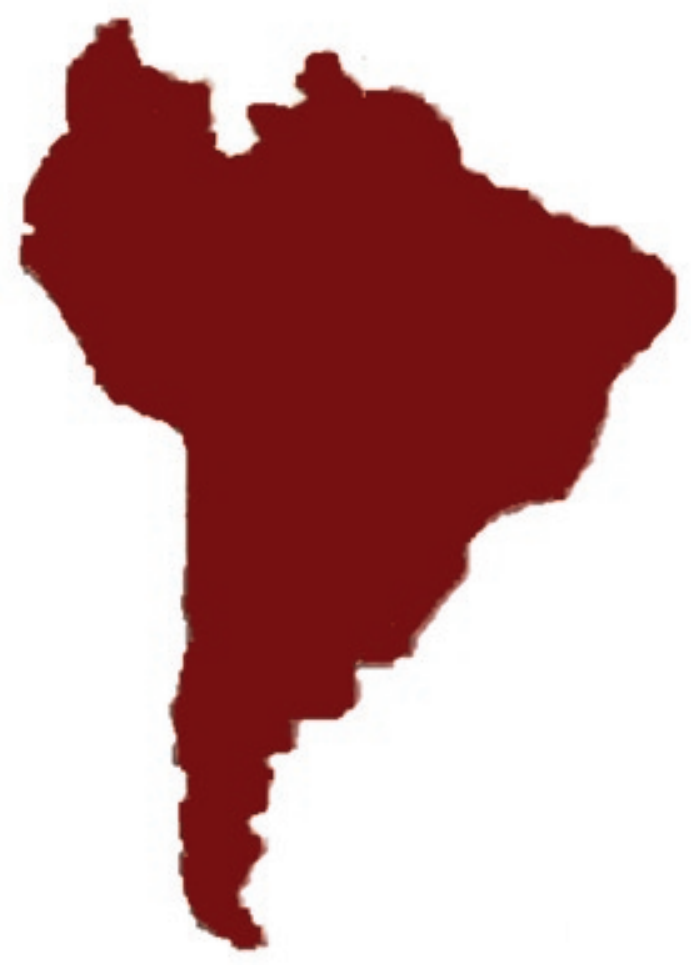

A América do Sul sem o Suriname inventa uma garra.

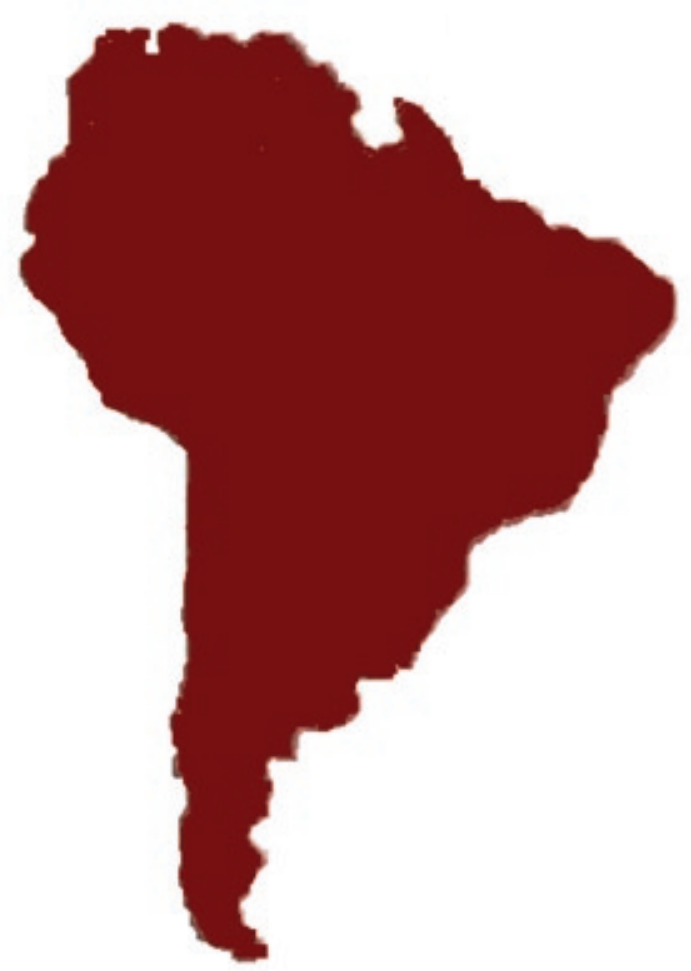

A América do Sul sem a Guiana: grita.

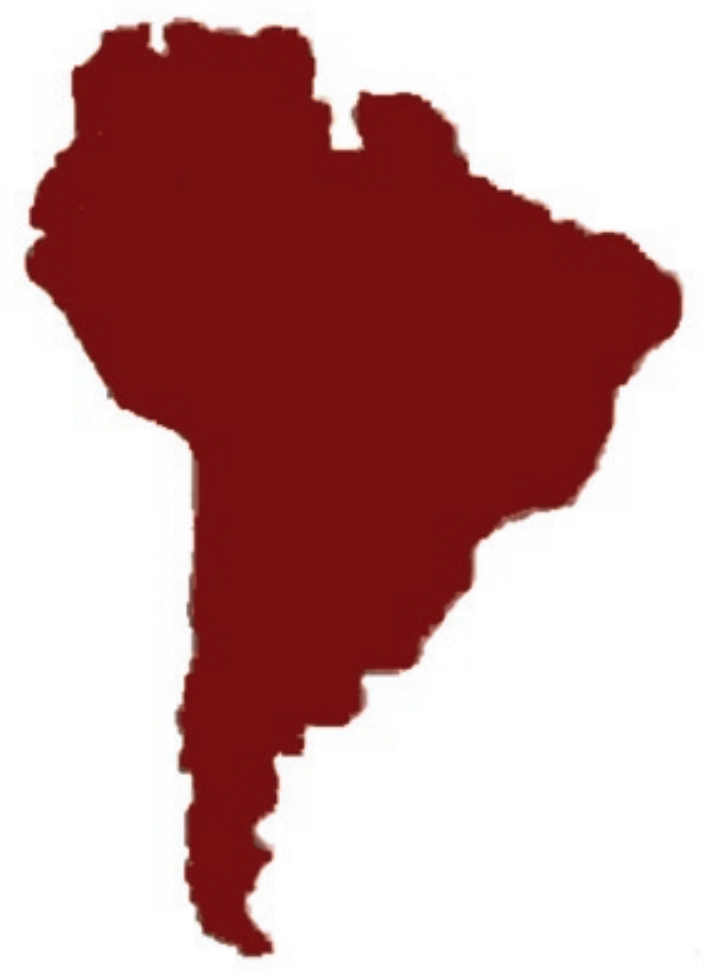

A América do Sul sem a Guiana Francesa dá um último aviso.

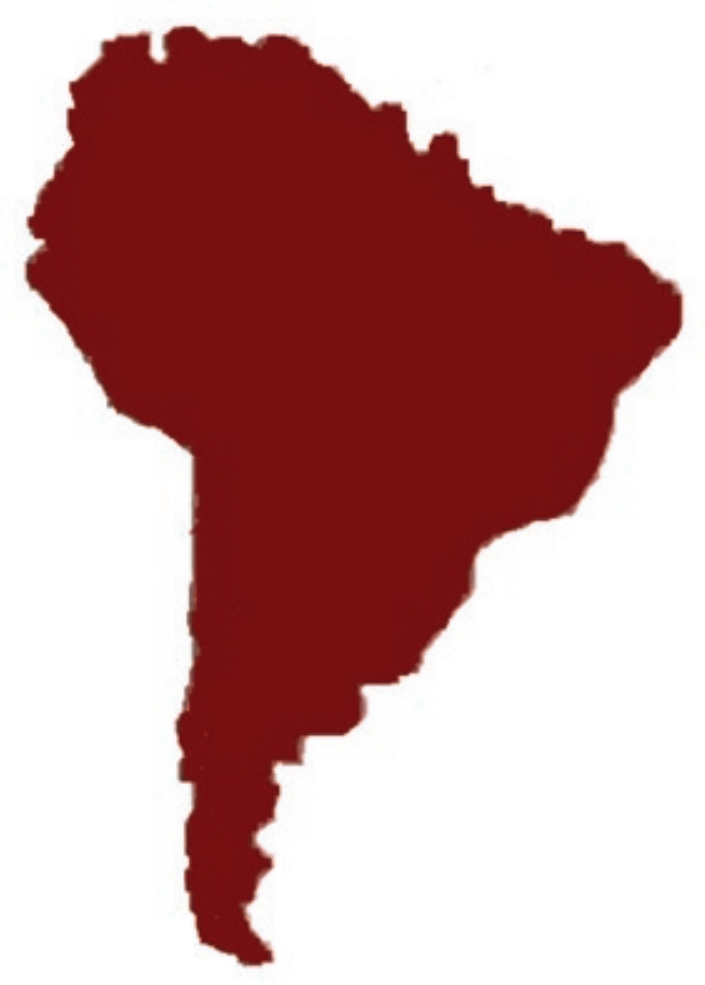




\section{A América do Sul sem o Brasil vira cavalo-marinho.}

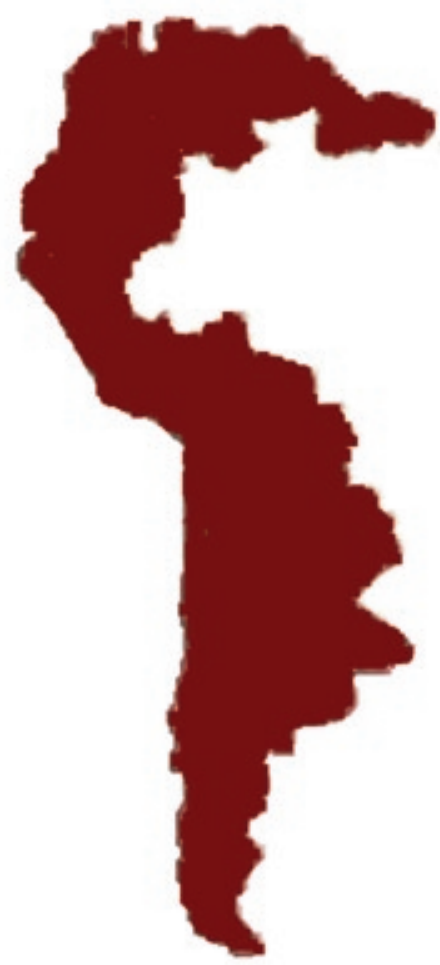

Ao contrário de outros animais fantásticos, o cavalo do mar não foi elaborado por combinação de elementos heterogêneos; não é mais que um cavalo selvagem cuja moradia é o mar e que só pisa a terra quando a brisa lhe traz o nada - talvez Bornéu - os pastores maneiam na costa as melhores éguas do rei e se escondem em câmaras subterrâneas; Simbad viu o potro que saía do mar e o viu saltar sobre a fêmea e ouviu seu grito (BORGES, 1974, p. 66).

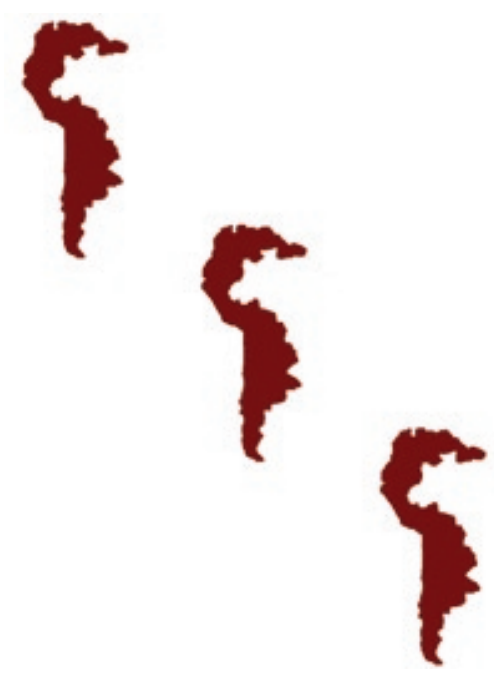

América do Sul, um sonho de lugar. Em labirintos, rodeios e devaneios, o sonhador da América por ela vaga escavando trilhas. Nela busca e se perde em labirintos de sossego e susto, lirismo e fantasia. Infinita América do Sul.
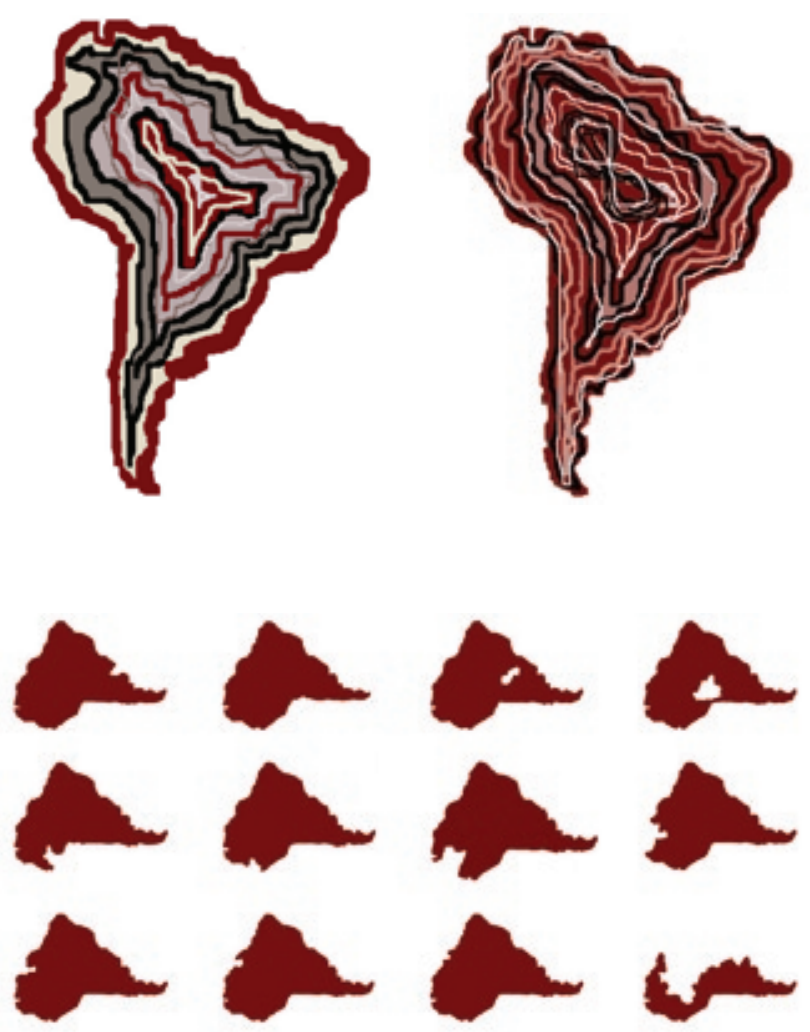
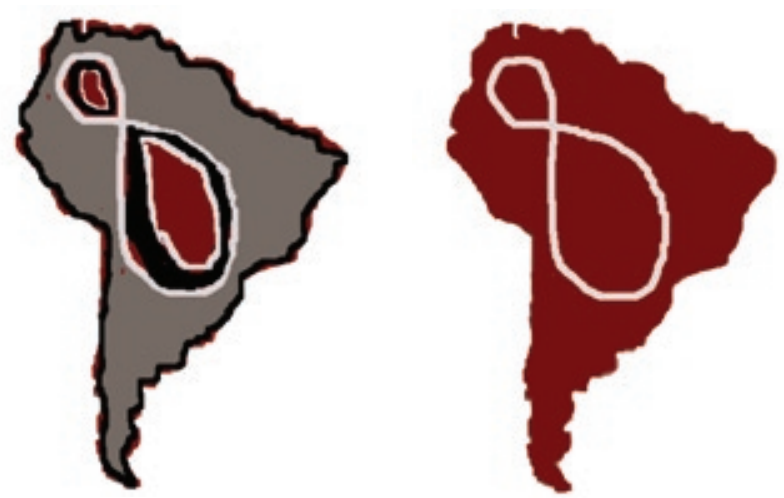

Américas amputadas que fizeram girar. Rumaram para o céu. Américas transformadas em nuvens. Paísesnuvens para contemplação. Puro devaneio.

\section{Referências}

BACHELARD, Gaston. A poética do espaço. São Paulo: Martins Fontes, 1989.

O direito de sonhar. São Paulo: Difel, 1986.

BORGES, Jorge Luis. O livro dos seres imaginários. Rio de Janeiro: Globo, 1974.

SYDENSTRICKER, Jack. Thresholds. Portais. 19892002. Rio de Janeiro. mimeo. 